\title{
The University Observatory, Glasgow
}

\author{
By Prof. W. M. Smart
}

\begin{abstract}
$\mathrm{HE}$ new observatory buildings of the University of Glasgow were formally opened on April 17 by Sir Arthur Eddington in the presence of a representative assembly presided over by the Chancellor of the University, Sir Daniel Stevenson, who was supported by the Principal, Sir Hector Hetherington, and Prof. John Walton, dean of the Faculty of Science. During the proceedings, Sir Arthur Eddington gave an address on "The Expansion of the Universe", in which he described his recent work, involving relativity and quantum theory, of predicting the actual rate of expansion.
\end{abstract}

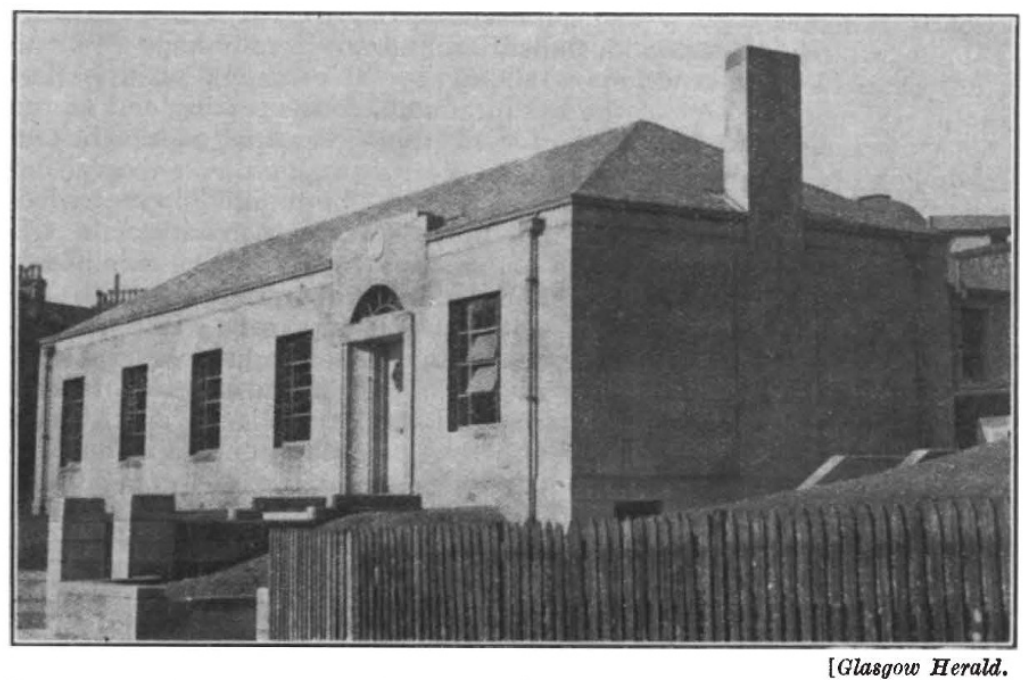

University Observatory, Glasgow. ToPs of the transit house and the 7-INCH DOME ARE SEEN ON THE RIGHT.

Owing to the exacting demands of modern observational astronomy as regards instrumental equipment and favourable atmospherical conditions, the new observatory (which is within a stone's throw of the main University departments) has been designed mainly for instructional purposes. The principal room of the main building is a library which can also be used for lantern lectures; a fine collection of fifty astronomical transparencies is mounted in this room. The other accommodation consists of a large instrument room and rooms for the director and his assistant. A 7-inch refractor carrying a small spectroscopic equipment is mounted on the high ground behind, and close by is a transit house. The observatory is also well equipped with subsidiary instruments. For two centuries and perhaps more, particularly during the last thirty or forty years, comprising the directorship of Prof. Becker, astronomy has proved, academically, to be of interest to a fair number of students, and it is hoped that the new facilities will further encourage astronomical study and research in the University.

The present observatory is the third astronomical institution established by the University. The old College of Glasgow was in possession of a telescope so far back as 1693 , and although astronomy was one of the subjects taught in these early days by the occupant of the chair of physics (or, from 1727, of natural philosophy), no proper accommodation for observational work was provided until 1756, when the University received the valuable bequest of the instruments belonging to Alex Macfarlane, a wealthy Jamaican merchant and a graduate of the University. The erection of an observatory-known as the Macfarlane Observatory - was immediately undertaken and the regius chair of practical astronomy was established in 1760 under a warrant of King George II. It is noteworthy that it was the establishment of the Macfarlane Observatory that led directly to James Watt's appointment as instrument maker to the University, and it was in this capacity that he effected the improvements in the steam engine that made his name world famous.

At the beginning of the nineteenth century the rapid extension of the city and the increasing industrialization of the neighbourhood made astronomical observa. tions almost impossible, and matters were not improved when some fifteen or twenty degrees of the meridian were securely blocked by the high steeple of a new parish church. It would appear that by 1820 the Macfarlane Observatory was reduced to little more than a centre of instruction, and it was there that Kelvin was taught the use of astronomical instruments.

In 1836 Prof. John P. Nichol was appointed to the chair-one of the applicants, it is of interest to note, was Thomas Carlyle. Nichol's success as a lecturer led to the formation of the Astronomical Institution of Glasgow, and a new observatory, with Nichol as director, was established as a private concern in 1841 at Dowanhill. The enthusiasm of the Glasgow citizens, however, waned with almost as great a rapidity as it had been stimulated, and in 1843 the University acquired the Observatory, together with the liabilities of the dead society. Nichol's successor was Prof. Robert Grant, whose two great publications-"The Glasgow Catalogue of 6415 stars" and the "Second Glasgow Catalogue of 2156 stars"-form a remarkable output for an observatory with such limited resources. The last effective directorship at Dowanhill was that of Prof. Becker, from 1893 until 1935. On his retirement, the University was confronted with the same problem which the academic authorities had to face, a century or more before, in connexion with the Macfarlane Observatory. The new observatory at Gilmorehill represents the solution. If auguries have any significance, the brilliant address of Sir Arthur Eddington and the benediction of an unclouded sun on the opening day should spell the beginning of a career of usefulness to the new institution in a University and City where astronomy and science as a whole have such long traditions. 